\title{
Feeding site location in birch aphids (Sternorrhyncha: Aphididae): The simplicity and reliability of cues
}

\author{
Graham W. HOPKINS and ANTHONY F.G. DIXON \\ School of Biological Sciences, University of East Anglia, Norwich NR4 7TJ, UK; e-mail: g.w.hopkins@bristol.ac.uk
}

Key words. Aphididae, Euceraphis betulae, Monaphis antennata, aphids, Betula pendula, birch, orientation, abaxial leaf surface, adaxial leaf surface

\begin{abstract}
To establish the importance of different cues for feeding site location in aphids, two birch-feeding species were given access to leaves that were either orientated normally or inverted. Euceraphis betulae used gravity and/or light as the main cue, and settled on the surface that was orientated down. Monaphis antennata additionally used leaf surface features to locate its feeding site, and approximately half of the individuals settled on the correct feeding surface whatever its orientation. This is one of the few examples of positive stimuli being used by aphids during feeding site location.
\end{abstract}

\section{INTRODUCTION}

Aphid species have characteristic feeding sites on their host plants, which they can locate by responding to gravity, light or features of the plant itself (Klingauf, 1970). Some aphids use gravity and/or light as the dominant cues (Dixon, 1976) but other aphids may initially respond to gravity, to move upwards towards the growing shoots, only to be repulsed by plant surface features, such that they ultimately settle elsewhere (Holtfreter, 1977). On many hosts, however, clones (Müller et al., 1974) and species (Jackson \& Dixon, 1996) utilise different feeding sites. In such instances different aphids must either differ in the cues that they utilise or they must respond differently to the same cues. This study examines this hypothesis, to identify the factors that aphids use to select their feeding sites.

\section{MATERIALS AND METHODS}

\section{Natural history}

Two species of birch-feeding aphids were used. Euceraphis betulae (Koch) is specific to Betula pendula Roth and feeds on the growing shoots and the undersides of leaves, presumably in response to their proximate quality (Hopkins, 1996). Monaphis antennata (Kaltenbach) utilises a number of birch species and the nymphs have very specific feeding sites, on the adaxial (upper) surfaces of leaves and petioles. It is thought that these feeding sites are enemy-free space (Hopkins \& Dixon, 1997). The nymphs of both species often disperse over a plant, and since they have long mouthparts they are thought to be physically capable of feeding from all parts of a leaf (Hopkins, 1996).

\section{Feeding-site location}

Nymphs of each species were introduced to cut-stems of $B$. pendula, with the leaves either orientated normally or inverted. To invert the leaves, the stems were held at an angle of $45^{\circ}$ with the shoot tip pointing up and rotated, such that the leaves were then inverted with the abaxial (lower-) surface uppermost. All but four leaves were removed, as were the growing tips, and the stems were $20 \mathrm{~cm}$ long. The leaves that remained on the stems were not a random selection of those originally present, but, apart from orientation, they appeared superficially similar to those removed.

A single fourth instar nymph was introduced to each stem, below the leaves, with twenty replicates of each species. The experiment was performed in a constant temperature room with long-day conditions $\left(20 \pm 1{ }^{\circ} \mathrm{C}, 16 \mathrm{~L}: 8 \mathrm{D}\right)$, illuminated from above. In the original stock cultures, which were on $B$. pendula in an unheated outdoor insectary, the $E$. betulae nymphs were feeding on the lower surfaces of leaves and the $M$. antennata were on the adaxial surfaces of petioles.

\section{RESULTS}

On the leaves that were orientated normally all of the $E$. betulae settled on the down-facing abaxial surface of a leaf, and all the $M$. antennata settled on the upwards-facing, or adaxial surface of a petiole (Fig. 1). On inverted leaves the majority of
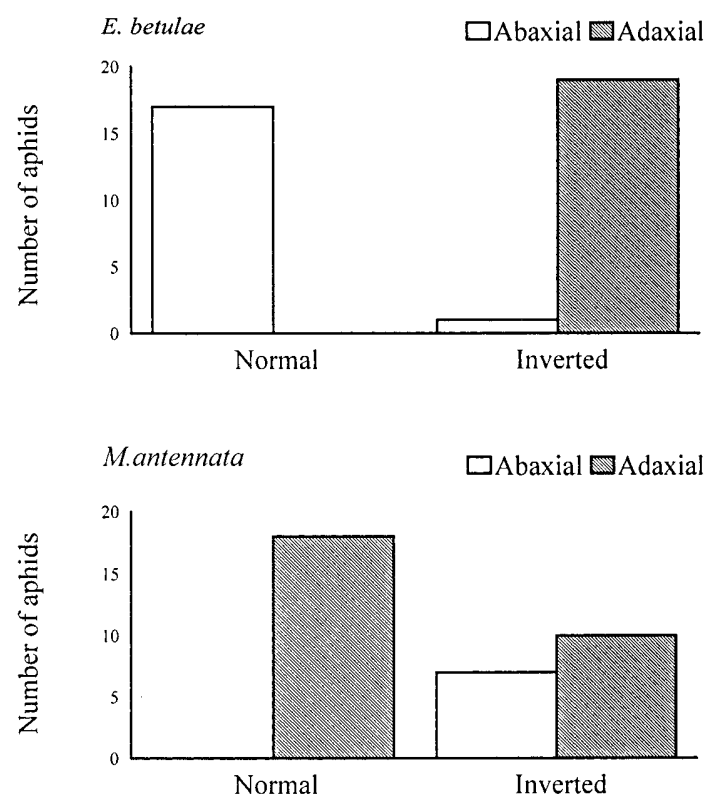

Fig. 1. The feeding positions of aphids after $14 \mathrm{~h}$ on normal and inverted leaves.

E. betulae settled on the surface which was then facing down, the adaxial surface. In contrast, approximately half of the $M$. antennata settled on the adaxial surface, which was now facing down, and half on the upwards-facing abaxial surface of the petioles of the inverted leaves. 
The behavioural response of the two species to leaf inversion differed (Fisher's exact test: $\mathrm{P}<0.001)$. E. betulae maintained its feeding orientation rather than re-locate its normal feeding surface ( 1 re-located the abaxial surface and 19 did not), but $M$. antennata showed a mixture of the two responses (10 re-located the adaxial surface and 7 did not).

\section{DISCUSSION}

The problem that aphids must overcome is how to utilise the available cues to identify reliably the feeding sites that maximise their fitness. The two species differ in the cues they predominantly respond to. $E$. betulae responds mainly to gravity and/or light, but $M$. antennata uses features of the plant itself, in addition to gravity and/or light.

The behaviour of $M$. antennata is notable because there are few examples of aphids responding positively to plant features during feeding site location (Müller et al., 1974), although positive stimuli are known to be important during the process of host plant selection (Dixon, 1997). In contrast, there are numerous examples of plant features having a negative impact on feeding site selection (e.g. Holtfreter, 1977; Bergman et al., 1991; Jackson \& Dixon, 1996). It is not known what features of the petiole that $M$. antennata is responding to, although it occupies the same feeding site on at least eight species of Betula (Blackman \& Eastop, 1994) and therefore the character is probably widespread within this plant genus.

\section{REFERENCES}

Bergman D.K., Dillwith J.W., Zarrabi A.A. \& Berberet R.C. 1991: Epicuticular lipids of alfalfa leaves relative to position on the stem and their correlations with aphid (Homoptera: Aphididae) distribution. Envir. Entomol. 20: 470-476.

Blackman R.L. \& Eastop V.F. 1994: Aphids on the World's Trees. CAB International, Oxford, $986 \mathrm{pp}$.

Dixon A.F.G. 1976: Factors determining the distribution of sycamore aphids on sycamore leaves during summer. Ecol. Entomol. 1: 275-278.

Dixon A.F.G. 1997: Aphid Ecology: An Optimisation Approach. Chapman \& Hall, London, $300 \mathrm{pp}$.

HoltFRETeR J. 1977: Das Zusammenwirken artspezifischer Verhaltensweisen bei der Besiedlung der Wirtspflanze durch ungeflügelte Virgines von Uroleucon tanaceti (L.) (Homoptera, Aphididae). Ann. Zool. 33: 463-475.

Hopkins G.W. 1996: Rarity in Tree Aphids. Unpubl. PhD. thesis, University of East Anglia, 175 pp.

HopkINS G.W. \& Dixon A.F.G. 1997: Enemy-free space and the feeding niche of an aphid. Ecol. Entomol. 22: 271-274.

JACKSON D.L. \& DIXON A.F.G. 1996: Factors determining the distribution of the green spruce aphid, Elatobium abietinum, on young and mature needles of spruce. Ecol. Entomol. 21: 358-364.

KunNGAUF V.F. 1970: Zur Wirtswahl der Grünen Erbsenlaus, Acyrthosiphon pisum (Harris) (Homoptera: Aphididae). Z. Angew. Entomol. 65: 419-427.

Müller F.P., Berger I. \& Herrmann A. 1974. Versuche über das Ansiedelungsverhalten zweier Rassen der Blattlaus Acyrthosiphon pisum (Harris) auf Vicia faba L. Biol. Zbl. 93: 675-686.

Received December 1, 1998; accepted May 9, 2000 